\title{
Postbuckling behavior of functionally graded CNT-reinforced nanocomposite plate with interphase effect
}

https://doi.org/10.1515/nleng-2017-0133

Received October 9, 2017; revised February 25, 2018; accepted July 5, 2018.

\begin{abstract}
The present paper is aimed to study the buckling and postbuckling response of functionally graded carbon nanotube (FG-CNT)- magnesium ( $\mathrm{Mg}$ ) nanocomposite plate with interphase effect. Interphase zone is characterized by employing a cohesive zone model for its elastic modulus and thickness. An equivalent solid fiber (ESF) of CNT and interphase is modeled and dispersed into the matrix material by utilizing random sequential adsorption (RSA) technique. The effective elastic properties of the nanocomposite are computed by finite element method (FEM) based numerical homogenization technique. The obtained elastic properties of nanocomposite are utilized to investigate the buckling and postbuckling behaviour of different functionally graded (i.e., FG) nanocomposite plates modeled by varying the volume fraction of CNT/ESF along thickness direction, under in-plane compressive loads. The non-linear formulation is based on first-order shear deformation theory and von Karman's assumptions. It is found that considering the interphase between CNT and Mg matrix would result in decrease in buckling load and postbuckling strength of FG-CNT-reinforced nanocomposite plate as compared to nanocomposite without interphase. It is also reported that the higher volume fraction of CNTs near top and bottom surfaces than the middle portion of nanocomposite plate provide better resistance to buckling and postbuckling.
\end{abstract}

Keywords: Carbon nanotube; Interphase zone; Elastic moduli; Representative volume element; Functionally graded nanocomposite plate; Postbuckling

\footnotetext{
Ashish Kumar Srivastava, Assistant Professor, Mechanical Engineering Department, Manipal University Jaipur, India, E-mail: ashishkumar.srivastava@jaipur.manipal.edu

*Corresponding Author: Dinesh Kumar, Associate Professor, Mechanical Engineering Department, Malaviya National Institute of Technology, Jaipur, India, E-mail: dkumar.mech@mnit.ac.in
}

\section{Introduction}

Carbon nanotubes (CNTs), one-dimensional (1D) tubular structure of hexagonally arranged carbon atoms exhibit exceptionally high aspect ratio in combination with low density, as well as high strength and stiffness. Theoretical and experimental studies in the literature have shown the unusual mechanical properties of CNTs - Young's modulus up to $1.2 \mathrm{TPa}$ and tensile strength in the range of 50$200 \mathrm{GPa}$ [1-3]. These extraordinary mechanical properties of CNTs make them ideal candidates for reinforcements in matrix materials to form light-weight nanocomposite having enhanced stiffness and strength [4]. In 2007, Esawi et al. [5] showed up to $50 \%$ and $23 \%$ enhancement in tensile strength and stiffness, respectively, of $5 \mathrm{wt} . \%$ CNTreinforced aluminum nanocomposite. To take full advantage of an reinforcement in CNT-nanocomposite, it is important to consider the issues related to the interphase between CNT and matrix material [6], and proper dispersion of CNTs in a matrix material [7].

The large aspect ratio of CNTs incline to transfer high load from the matrix material to CNTs which in turn depends on the interphase zone between them. Therefore, the effective mechanical properties of the CNT-reinforced nanocomposite depend on the strength of the interfacial bonding between CNT and matrix material. Carbon atoms in a CNT are chemically stable because of the aromatic nature of bonding between carbon atoms, and mainly there exist van der Waals (vdW) interaction between the CNTs and matrix material. Tsai et al. [8] introduced a threephase model of the CNT-reinforced nanocomposites by modeling the interphase zone between the CNT and polyimide as a separate phase and evaluated the stiffness properties of the interphase zone by utilizing the non-bonded energy based on Lennard-Jones (LJ) potential. Shokrieh and Rafiee [9] used 3D non-linear spring elements (named as COMBIN39 element) of FEM based software ANSYS to model the interphase zone and developed an equivalent long fiber consisting of CNT and interphase zone to predict the stiffness properties of the CNT/polymer nanocomposite. Hernández-Pérez \& Avilés [10] reported that the thick- 
ness of the interphase zone strongly influences the stiffness properties and stress distribution of the nanocomposite, especially for matrix materials having low elastic modulus. The separate modeling of interphase zone from the CNTs in a matrix material leads to high computational cost which can be minimized by modeling a CNT along with adjoining interphase region into an equivalent solid fiber (ESF). Then the ESF and matrix material are assumed to be perfectly bonded in a continuum model. The effect of weak interface between the CNT and matrix material is considered in the characterization of ESF [11]. Shokrieh and Rafiee [12] suggested not to compare the stiffness properties of ESF-reinforced nanocomposite obtained from finite element modeling with those predicted by the micromechanics based rule of mixtures, since the latter doesn't consider the effect of perfectly bonded interphase zone between CNT and matrix material and hence overestimates the stiffness properties. Rafiee \& Mahdavi [13] reported that the Young's modulus of ESF considering the effect of interphase region is nearly $38 \%$ lower than that of isolated CNT.

Since the interphase region between CNT and matrix material has a significant effect on the effective elastic properties of nanocomposite [14], thus it is necessary to study its mechanical behavior on a proper theoretical background. A generalized equation of cohesive zone model for the interphase force field based on the vdW interaction between CNT and polymer matrix material was proposed by Jiang et al. [15]. Tan et al. [16] incorporated the nonlinear cohesive law, derived by Jiang et al. [15], and concluded that improvement in the mechanical behavior of the CNT-nanocomposite is observed only at small strain, but at large strain such improvements vanish because of the complete debonding of CNTs from the matrix material. Zhao et al. [17] also utilized the same cohesive zone model for the interphase region to predict the cohesive energy and equilibrium distances for CNT/graphene, CNT/substrate and two crossing CNTs by continuum modeling of the van der Waals interaction between them. Further, Zhang et al. [18] modeled a functionally graded variation of interphase (FGVI) using the same cohesive zone model and studied the effect of FGVI on the stiffness properties of nanocomposite and cohesive strength.

Further, the poor dispersion of CNTs in a matrix material results in aggregation of CNTs that in turn lead to adverse effect on the elastic properties of nanocomposite material [19]. Different experimental techniques have been contrived by the researchers to disperse the CNTs in matrix material[20,21] uniformly. Rahman et al. [22] reported that the proper distribution of CNTs in matrix material leads to the improvements in the tensile properties of
CNT-nanocomposite. Wang et al. [23] concluded that good dispersion of CNTs can be obtained by reinforcing short CNTs in a matrix material. In addition, in contrast to stiff and straight CNTs of large diameter, the bent and entangled CNTs having small diameter are harder to disperse uniformly in the matrix material with the increase in CNT content [24]. The uniform dispersion of CNTs in a matrix material can be modelled through the random sequential adsorption (RSA) algorithm [25], which is widely applied to model an RVE of conventional composites containing random fibers [26, 27]. Pan et al. [28] employed RSA technique to study the effect of the fiber interaction on overall stiffness properties of composite materials. Bailakanavar et al. [29] proposed a hierarchical RSA algorithm to generate unit cells having randomly distributed fillers to achieve the fiber volume fraction up to $45 \%$ for the aspect ratios as high as 20. Abd El-Rahman and Tucker III [30] utilized the radial and shortest distance distribution functions to simulate the randomness of long fibers (i.e., $l / d=100$ ). Recently, Song et al. [31] developed RVE models containing a 3D network of reinforcements within the RVE and demonstrated that computationally homogenized models with material periodic conditions are independent of RVE size and proved that homogenized results are computationally efficient compared to the statistical models. Boolean based RSA technique proposed by Liu et al. [32] anticipates the position and orientation of non-overlapping fibers of arbitrary shapes without entering into the iterative procedure, thus found to be more general and computationally effective.

Apart from the uniform dispersion of CNTs, another important methodology to further improve the mechanical properties of CNT-reinforced nanocomposites in a particular direction is through proper alignment of CNTs [33]. Many researchers have devised different experimental techniques to align the CNTs in matrix materials. For instance, Ogasawara et al. [34] fabricated the aligned CNT/epoxy prepeg by using hot-melting method and reported the enhanced Young's modulus and tensile strength than those of nanocomposites produced by utilizing conventional CNT/epoxy mixing methods. Bradford et al. [35] developed a novel shear pressing method to quickly obtain the aligned CNT preforms for nanocomposite fabrication. On the other hand, to model and characterize the aligned CNT-reinforced nanocomposites, researchers have also performed simulations by forming RVEs containing aligned CNTs [36]. Joshi \& Upadhyay [37] simulated the different alignments of double-walled CNT layers in the nanocomposite and reported that higher volume fraction of double-walled CNTs in matrix material leads to more noticeable agglomeration resulting in nonlinear behaviour of 
axial and lateral moduli of nanocomposite material. In addition, micromechanics approach has also been utilized to study the elastic properties of aligned CNT-reinforced nanocomposite [38].

Exceptionally high strength and stiffness properties of CNTs and its effect on the mechanical and/or thermal properties of CNT-nanocomposite at nanoscale further necessitates the study of behaviour of various structural elements at macroscale, such as beams, plates and shells that are made of CNT-reinforced nanocomposite [39-42]. One of the most interesting characteristics of actual thin platelike structures is to be able to defy larger compression and/or shear loads after reaching bifurcation point i.e., buckling point. The evaluation of the full load-carrying capacity of these structures beyond the bifurcation point has been an area of intense study. Different buckling and postbuckling studies of CNT-reinforced nanocomposite plates are available in the literature. For instance, Shen \& Zhu [43] analyzed the sandwich plates with CNT-reinforced nanocomposite face sheets resting on elastic foundations to predict its postbuckling behaviour under thermal environment. Foroughi et al. [44] studied the mechanical buckling behaviour of thick CNT-reinforced nanocomposite plates resting on an elastic foundation. Malekzadeh \& Shojaee [45] have studied the CNT-reinforced buckling behavior of quadrilateral laminated plates. In 2009, Shen [46] utilized the MD simulations to predict the size and temperature dependent material properties of CNT and studied the nonlinear bending behaviour of CNTreinforced nanocomposite plate. It was established that the load-bending moment curves of the nanocomposite plate can be significantly increased by the functionally graded reinforcement of CNTs. Unlike the traditional CNTreinforced nanocomposite plates, functionally graded distribution of CNTs in matrix materials possess desired material properties $[47,48]$. To estimate the stiffness properties of functionally graded CNT (i.e., FG-CNT) reinforced nanocomposites, the micromechanical models, such as Eshelby-Mori-Tanaka scheme [48, 49], and the extended rule of mixtures [50] have been successfully applied by many researchers. Shen \& Zhang [51] predicted the thermal buckling and postbuckling behavior of FG-CNT reinforced nanocomposite plates. Zhang et al. [52] studied the buckling behavior of FG-CNT reinforced thick skewed nanocomposite plate using improved element-free moving least-square Ritz method. Using the same approximations for the field variables in the Ritz method, the postbuckling behavior of the FG-CNT nanocomposite plate resting on Pasternak foundations was studied by Zhang and Liew [53], and plate with edges elastically restrained against translation and rotation was analyzed by Zhang et al. [54].

In this paper, a cohesive zone model is utilized to characterize the interphase zone between CNT and matrix materials in terms of its Young's modulus and thickness. Thereafter, an equivalent solid fiber (ESF) of CNT along with interphase zone is modeled. ESFs are distributed with random-positions \& -orientations and with random-positions but aligned in the matrix material by employing Boolean based RSA technique to make a nanocomposite. The effective elastic properties of the nanocomposite material are evaluated with the application of finite element method (FEM) based numerical homogenization technique for different volume fractions of CNT reinforcement. The obtained stiffness properties of nanocomposite material are further utilized to model different non-homogeneous functionally graded (i.e., FG) CNT-reinforced nanocomposite plates by varying the volume fraction of CNT along thickness direction. The buckling and postbuckling behaviour of FG-CNT-reinforced nanocomposite plate, with and without considering interphase effect, under in-plane compressive loading are studied. The non-linear FEM formulation for the nanocomposite plate analysis was based on the first-order shear deformation theory and von Karman's assumptions. Arclength method is utilized to solve the resulting nonlinear finite element algebraic equations. Different studies are performed to study the effects of perfect and imperfect bonding between CNT and matrix material, type of CNT-distribution in FG plate, CNT-alignment, geometric parameters (i.e., aspect ratio and width-to-thickness ratio), boundary conditions and type of loading (i.e., uniaxial and bi-axial compression) on the postbuckling behaviour of FG-CNT-reinforced nanocomposite plate.

\section{Equivalent Solid Fiber Model}

The same cohesive zone model based on vdW interactions between CNT and matrix material described by Jiang et al. [15] and also utilized by Srivastava \& Kumar [55] to predict the thickness $\left(h_{0}\right)$ and elastic modulus $\left(E_{I}\right)$ of interphase zone is employed in the current study to evaluate the linear elastic behavior of equivalent solid fiber (ESF). The detailed description of this model to find the thickness $\left(h_{0}\right)$ and elastic modulus $\left(E_{I}\right)$ of interphase zone can be found in Ref. [55], and for ready reference the important equations are given in sequel. 
The equilibrium distance between the CNT and matrix material (i.e., $h_{0}$ ) is given as:

$$
h_{0}=0.8584 \sigma_{I} .
$$

where, $\sigma_{I}$ is referred as vdW radius and represents the distance at which the intermolecular potential between the two atoms vanishes and it measures how close two nonbonding atoms can approach.

The elastic modulus of the interphase region (i.e., $E_{I}$ ) for the equilibrium position (i.e., $r=h_{0}$ ), is given by:

$$
\begin{aligned}
& E_{I}=h_{0} \cdot \frac{2}{3} \pi^{2} \rho_{m} \rho_{C N T} \sigma_{I} \epsilon_{I}\left[24 R_{o}\left\{\left(\frac{\sigma_{I}}{r}\right)^{11}-\left(\frac{\sigma_{I}}{r}\right)^{5}\right\}\right. \\
& \left.+9 \sigma_{I}\left\{\frac{6}{5}\left(\frac{\sigma_{I}}{r}\right)^{10}-\left(\frac{\sigma_{I}}{r}\right)^{4}\right\}\right]
\end{aligned}
$$

where $r$ and $R_{o}$ represent the distance between the CNT \& matrix material and the outer radius of CNT, respectively, and the area density $\left(\rho_{C}\right)$ and volume density $\left(\rho_{m}\right)$ specify the number of carbon atoms per unit surface area of CNT and number of atoms per unit matrix volume, respectively. The well depth $\left(\epsilon_{I}\right)$ and vdW radius $\left(\sigma_{I}\right)$ of the LJ potential curve for the interphase zone between CNT and that of matrix material can be evaluated by employing the widely used Lorentz-Berthelot (LB) mixing rule [56, 57].

After obtaining the Young's modulus $\left(E_{I}\right)$ and thickness $\left(h_{0}\right)$ of the interphase zone, the cylindrical continuum structure of CNT and the interphase zone between CNT and matrix material is replaced by an ESF in accordance with micromechanics assumptions, and that is further utilized to form an RVE, as shown in Fig. 1. While constructing ESF, the same axial force is applied on the CNT \& interphase zone and the ESF to obtain the effective radius of ESF by equaling axial deformation of the CNT \& interphase zone and the ESF [13].

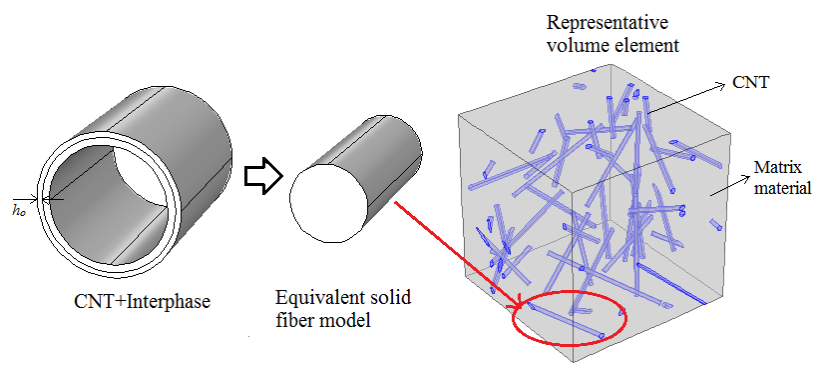

Fig. 1: Multiscale modeling procedure to form the representative volume element reinforced by equivalent solid fibers (ESF) made of CNT and interphase zone.

Therefore, the axial force applied on the ESF is given as:

$$
F_{E S F}=F_{C N T}+F_{I N T},
$$

where, $F_{C N T}$ and $F_{I N T}$ are the fractions of applied force (i.e., $F_{E S F}$ ) borne by CNT and interphase zone, respectively. Similarly, the same axial deformation of CNT, interphase zone and ESF can be represented as

$$
\Delta L_{C N T}=\Delta L_{I N T}=\Delta L_{E S F},
$$

where, $\Delta L$ represents the change in longitudinal length.

By solving Eqs. (3) \& (4) for the radius of ESF (i.e., $r_{E S F}$ ), the following Eq. (5) is obtained in terms of Young's modulus $(E)$ and cross-section areas of CNT (i.e., $A_{C N T}$ ) and interphase region (i.e., $A_{I N T}$ ).

$$
E_{E S F} A_{E S F}=E_{C N T} A_{C N T}+E_{I n t} A_{I N T},
$$

or,

$$
E_{E S F} r_{E S F}^{2}=E_{C N T}\left(r_{o}^{2}-r_{i}^{2}\right)+E_{I N T}\left(r_{3}^{2}-r_{o}^{2}\right),
$$

where, $r_{i}\left(=R-\frac{t}{2}\right)$ and $r_{o}\left(=R+\frac{t}{2}\right)$ are the internal and external radii, respectively, of the equivalent continuum hollow CNT. Where the wall thickness $(t)$ is taken as $0.34 \mathrm{~nm}$, and the radius of atomistic CNT model $(R)$ is computed using

$$
R=\frac{\sqrt{3} b}{2 \pi} \sqrt{m^{2}+n^{2}+m n}
$$

wherein $b$ is C-C bond length, taken as $0.142 \mathrm{~nm}$, and $n$ $\& m$ represent the chiral index of CNT. Further, in Eq. (5) $r_{3}$ represents the outer radius of the interphase zone calculated as $\left(r_{o}+h_{o}\right)$.

To predict the radius of ESF using Eq. (5), the required value of Young's modulus of ESF (i.e., $E_{E S F}$ ) is computed by using rule of mixtures, as given below:

$$
E_{E S F}=V_{C N T} E_{C N T}+\left(1-V_{C N T}\right) E_{I N T},
$$

where $V_{C N T}$ represents the volume fraction of CNT in CNTinterphase system and it is computed as

$$
V_{C N T}=\frac{\left(r_{o}^{2}-r_{i}^{2}\right)}{\left(r_{3}^{2}-r_{i}^{2}\right)}
$$

\section{Modeling of ESF-Reinforced RVE}

\subsection{Generation of RVE with non-overlapping ESFs}

To estimate the elastic properties of CNT-reinforced nanocomposite, it is prerequisite to create an RVE that captures the major features of underlying CNT reinforced in a matrix material $[58,59]$. In the present study, a periodic cubic RVE containing randomly-oriented and -positioned 
ESFs is utilized to evaluate the homogenized elastic properties of the nanocomposite material. ESFs are described by its origin $O$ and Euler angles $\theta \& \phi$ in the $x y z$ coordinate system, as shown in Fig. 2. The integer values of Euler angles $\theta \in(0,2 \pi)$ and $\varnothing \in\left(\frac{-\pi}{2}, \frac{\pi}{2}\right)$ are chosen in such a way that these values are randomly and uniformly distributed in the ranges specified, as per the procedure described by Abd El-Rahman and Tucker III [30]. To model the RVE, Boolean based RSA algorithm proposed by Liu et al. [32], also shown in Fig. 3, is employed to generate a set of non-intersecting ESFs in the RVE. To maintain the periodicity of the RVE, 26 periodic images of an ESF are generated in a 3-D space contained within $x, y, z= \pm a$ with origin taken at the end of that ESF, as illustrated in Fig. 4. Further, as mentioned in Fig. 3, a new ESF is kept on adding into the RVE till the volume fraction of CNT (i.e., $V_{f}$ ) reaches to the reference volume fraction (i.e., $V_{\text {ref }}$ ), and when the reference volume fraction is reached, the parts of ESFs lying outside the RVE boundary are chopped off to form the resulting RVE, as shown in Fig. 5(a). The same methodology is also utilized to from RVEs with randomlypositioned, but aligned, as shown in Fig. 5(b).

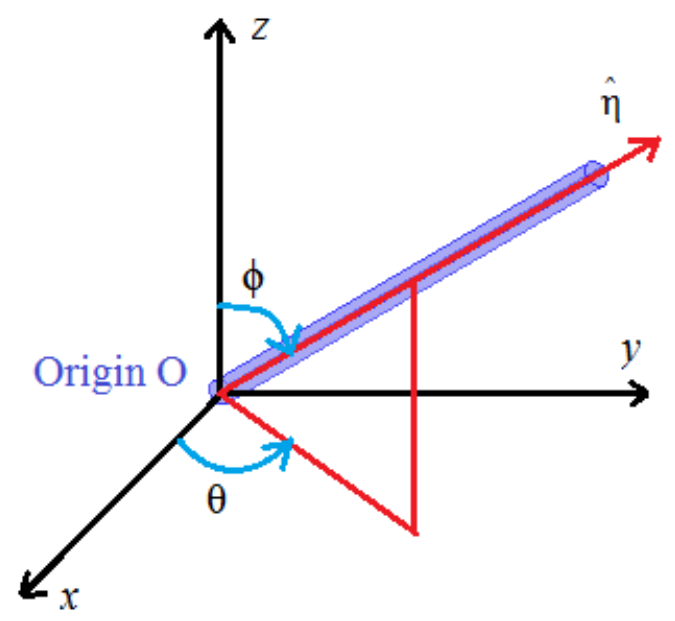

Fig. 2: Co-ordinate system and definitions of $\theta$ and $\varphi$ for an ESF.

\subsection{Numerical homogenization}

The RVE, constituting of ESFs and matrix material is a heterogeneous nanocomposite medium at nano scales, is to be used to estimate the effective stiffness properties of nanocomposite material that is considered as a homogeneous medium at larger scales (i.e., micro, meso or macro scales). Consequently, it is necessary to employ a homogenization technique to find a homogeneous medium equiv-

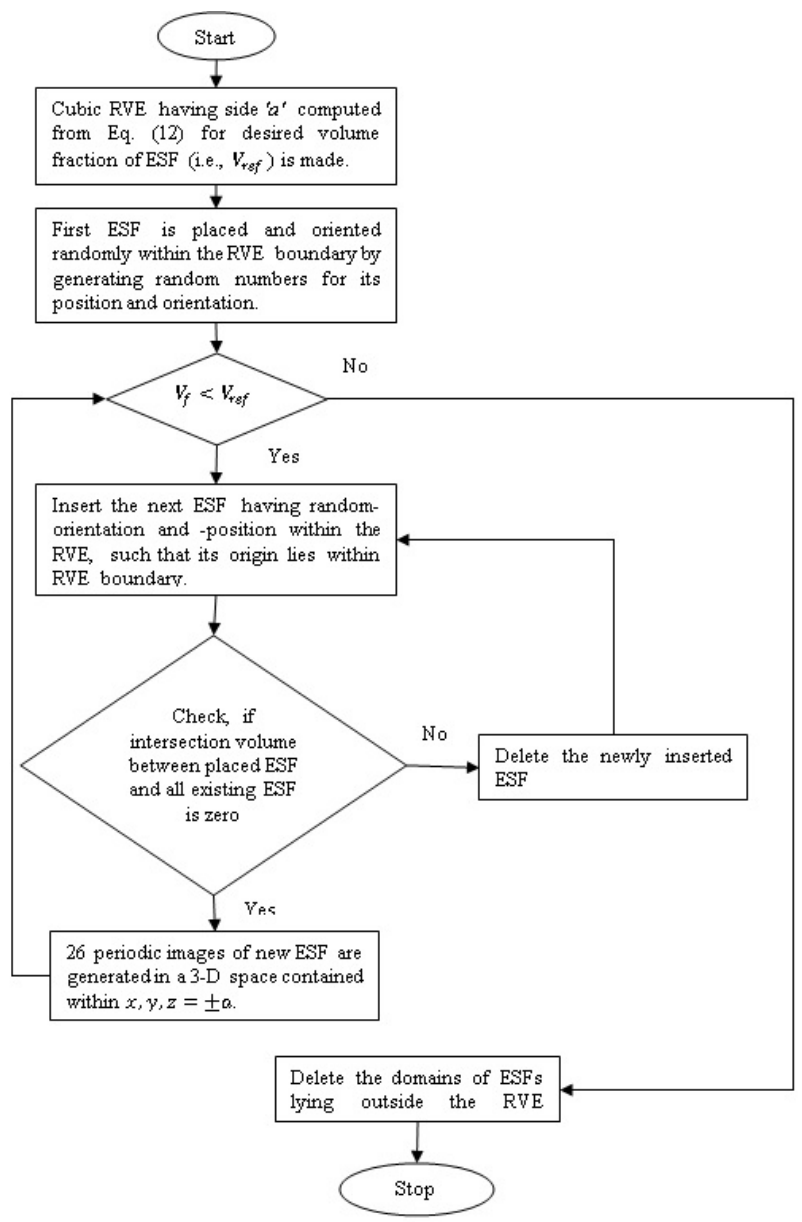

Fig. 3: Boolean based RSA algorithm to generate periodic RVE.

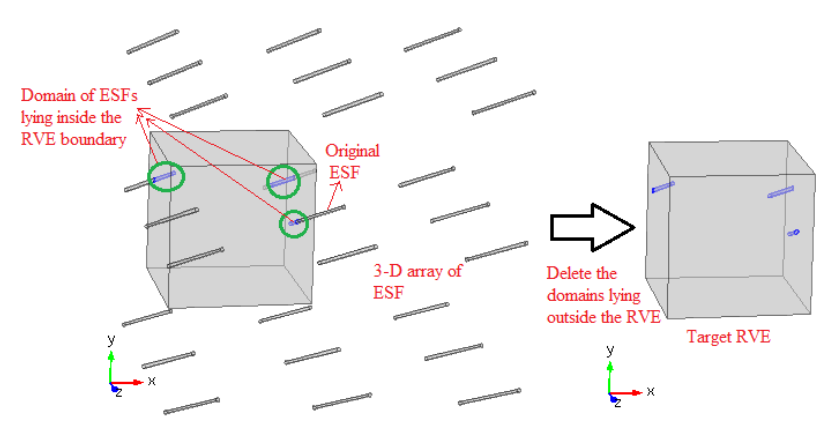

Fig. 4: Stepwise procedure to model the periodic RVE reinforced by ESFs.

alent at micro, meso or macro scales to the original heterogeneous nanocomposite at the nano scale. The actual nonhomogeneous stress and strain fields within the heterogeneous RVE are volume-averaged to get stress and strain in the equivalent homogeneous medium using finite element method (FEM). With the basic assumptions of linear elasticity of CNTs and matrix materials, the homogenization method followed in the present study for evalu- 


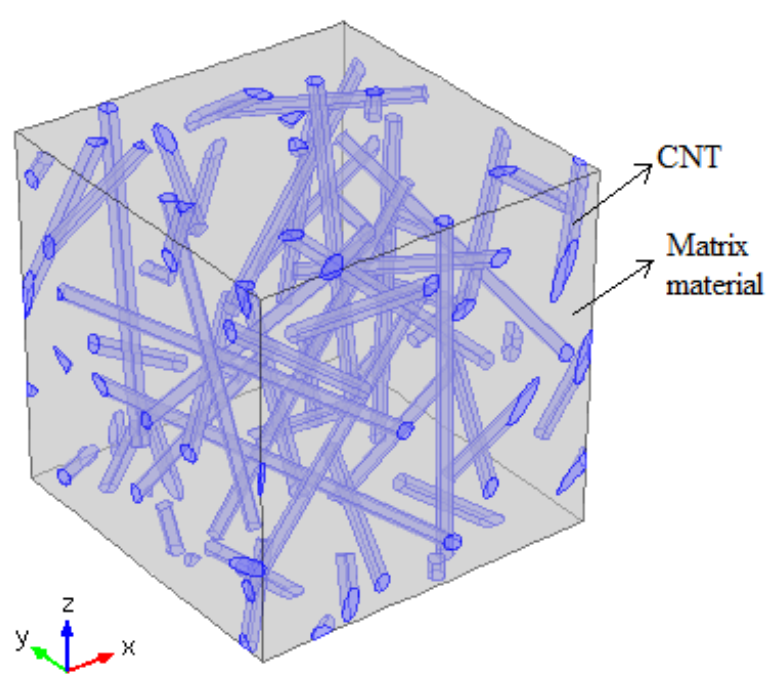

(a)

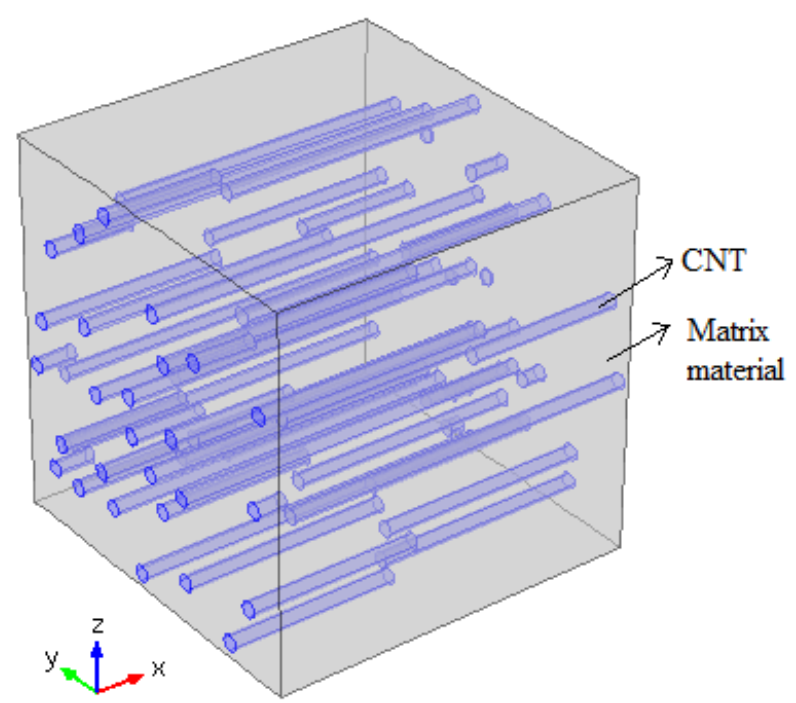

(b)

Fig. 5: Periodic RVE containing (a) randomly-oriented and positioned ESFs (b) aligned and randomly-positioned ESFs.

ating average stress and strain over the RVE, and subsequently calculating the effective moduli (that describe the average material properties) of the actual heterogeneous nanocomposite is same as described in Kumar \& Srivastava [4].

\section{Micromechanics Based Analytical Model}

In this section a semi-empirical approach employed for the validation of results obtained from FEM based proce- dure, discussed in Section 3.2, is described. Under the assumption of perfect bonding between the reinforcement and matrix, Tsai-Pagano method has been widely used to estimate the elastic properties of 3D-oriented nano-filler reinforced nanocomposites $[60,61]$ using the transverselyisotropic properties of a single-CNT RVE. In the present study too, under the same assumption of a perfect bonding between ESFs (equivalent solid fibers) and matrix materials, Tsai-Pagano model is utilized to validate the FEM based results for 3D-oriented ESFs reinforced nanocomposites. It is to mention here that the FEM-based results are considered in the subsequent study on postbuckling behavior of FG-CNT nanocomposite plate, in Section 9.2.

The Tsai-Pagano model is given by the following equations:

$$
E=\frac{3}{8} E_{1}+\frac{5}{8} E_{2}
$$

where, $E$ represents the Young's modulus of the resulting isotropic nanocomposites containing 3D-oriented ESFs reinforcements; $E_{1}$ and $E_{2}$ are the longitudinal and transverse Young's modulus of a single-ESF reinforced RVE. Analytically, $E_{1}$ and $E_{2}$ can be estimated by the Halphin-Tsai method using following equation:

$$
\frac{E_{1(\text { or } 2)}}{E_{m}}=\frac{1+\xi \eta v_{f}}{1-\eta v_{f}} \text {; where } \eta=\frac{\frac{E_{f}}{E_{m}}-1}{\frac{E_{f}}{E_{m}}+\xi},
$$

where, the reinforcing factor $\xi$ depends on reinforcement geometry (i.e., circular or rectangular) and its packing pattern, and further it has different expressions to evaluate different composite moduli (i.e., bulk modulus, transverse shear modulus, longitudinal shear modulus) and thus also depends on the corresponding loading conditions [62]. The values of $\xi$ in present work are taken as $\frac{2 L}{d} \& 2$ for evaluating $E_{1}$ and $E_{2}$, respectively, for circular reinforcement packed in square array[63]. The subscripts ' $m$ ' and ' $f$ ' correspond to the matrix and the reinforcement (i.e., ESF), respectively. The volume fraction $v_{f}$ of the reinforcement in the RVE is calculated using

$$
v_{f}=\frac{V_{E S F}}{V_{R V E}}=\frac{\pi r_{E S F}^{2}}{\left(a^{2}-n \pi r_{E S F}^{2}\right)}
$$

where, $r_{E S F}$ is the radius of the ESF, $a$ represents the side of square RVE, and $n$ is the number of ESFs. 


\section{Functionally graded (FG) ESF-reinforced nanocomposite plate}

In the present study, an actual FG-ESF-reinforced nanocomposite plate, with continuously varying material properties in thickness direction, is modeled as a laminate composed of multiple perfectly-bonded nanocomposite layers with varying volume fraction of ESFs. Three types of FG-ESF-reinforced nanocomposite plates are modeled by varying the volume fraction of ESF along thickness direction, as shown in Fig. 6, and are designated as FG-A, FG-B and FG-C, where FG-A refers to the model with volume fraction of ESF decreasing linearly from maximum at outermost layer to minimum at innermost layer of nanocomposite laminate, the reverse of FG-A (i.e., linear variation of volume fraction of ESF from maximum at innermost layer to minimum at outermost layer) represents FG-B, and the model FG-C contains uniform volume fraction of ESF in each layer and thus this model is also referred as the uniformly distributed ESF-reinforced nanocomposite plate.

\section{Finite Element Procedure for Postbuckling Study of FG-ESF-reinforced Nanocomposite Plate}

The non-linear FEM formulation is based on the firstorder shear deformation theory (FSDT) along with geometric nonlinearity as per von-Karman's assumptions. Eightnoded shell element (i.e., SHELL281), having six degrees of freedom at each node, viz. three translations and three rotations in $x, y$ and $z$ directions, is employed to discretize the FG-ESF-reinforced nanocomposite plate. The obtained set of nonlinear algebraic equations is solved by arc-length method. A complete formulation for postbuckling analysis is provided by Kubiak [64], but for the sake of ready reference a brief description of the procedure is given below.

ANSYS uses incremental approach to solve the problems incorporating geometric non-linearity. In incremental approach, load is applied in small increments in order to make the structure respond linearly during each increment [65]. But incremental analysis must include some type of imperfection, in the geometry, material, or alignment of loads, otherwise it will track the linear solution,

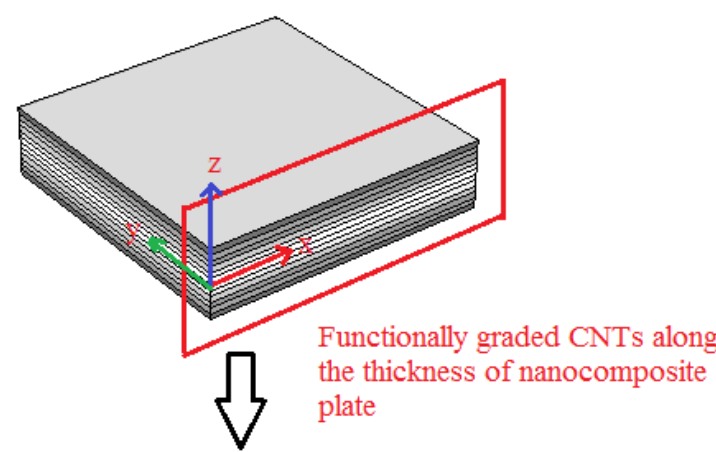

(a) FG-A

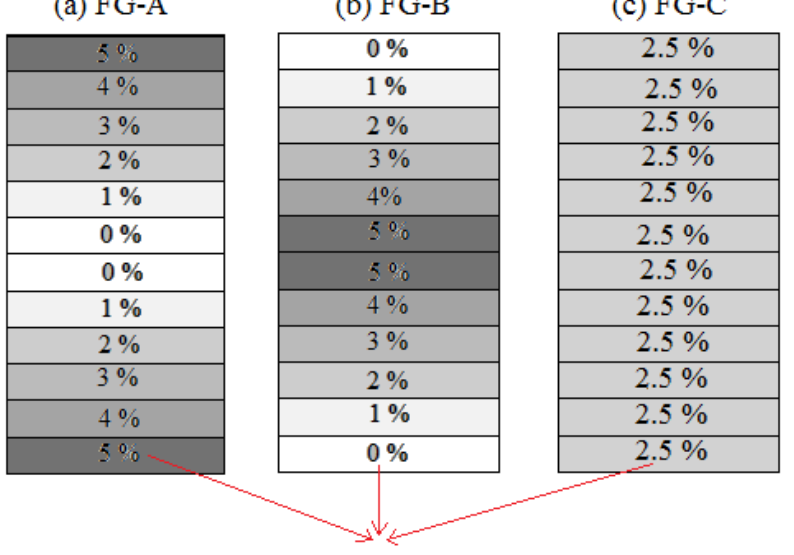

Percentage of CNT reinforcement
Fig. 6: Modeling of actual FG-CNT-reinforced nanocomposite plate into a laminate composed of multiple perfectly-bonded nanocomposite layers.

revealing no bifurcations or limit point. For smaller imperfections, the incremental approach will follow more closely the path of perfect structure. Whereas, for a structure with large imperfections, its post-critical path will deviates more from that of the perfect structure $[66,67]$. Thus, studies involving buckling and postbuckling analysis of thin plate like structures under in-plane compressive loads also need some kind of imperfections in terms of out-of-plane displacement (provided either by a little transverse force or by specifying a small initial displacements) to initiate buckling response. Therefore, in the present study, the buckling and postbuckling analysis of FG-ESF-reinforced nanocomposite plate are performed in two stages: (1) eigen value linear buckling analysis, and (2) nonlinear (geometric) postbuckling analysis. In the eigen-value buckling analysis, the buckling load and corresponding buckling mode are evaluated, and thereafter, the buckled mode shape is further employed to provide an initial tiny perturbation/imperfection into the FG-ESF-reinforced nanocomposite plate. Subsequently, the nonlinear postbuckling analysis of FG-ESFreinforced nanocomposite plate using FEM is performed 
by utilizing an iterative procedure wherein the in-plane compressive load on the FG- ESF-reinforced nanocomposite plate is increased gradually in each successive step, and the corresponding out-of-plane deformation is obtained.

The nonlinear algebraic equations of a discrete system are given by:

$$
[\bar{K}(u)]\{u\}-\{P\}=0
$$

where $[\bar{K}]$ is the tangent stiffness matrix depending on the nodal displacement $\{u\}$, and net nodal force vector $\{P\}$.

At a particular load step, Eq. (12) for the $i^{\text {th }}$ iteration can be rewritten as:

$$
\left[\bar{K}_{i}\right]\left\{\Delta u_{i}\right\}=\left\{\Delta P_{i}\right\}
$$

where the increment of displacement (i.e., $\Delta u_{i}$ ) is assumed to comply the following expression:

$$
\left\{u_{i+1}\right\}=\left\{u_{i}\right\}+\left\{\Delta u_{i}\right\}
$$

and,

$$
\left\{\Delta P_{i}\right\}=\zeta\left\{P^{a}\right\}-\left\{P_{i}^{r}\right\},
$$

wherein the $\left\{P^{a}\right\}$ represents the applied nodal force vector adjusted via the load factor $\zeta(-1<\zeta<1)$ in the subsequent iterative process, and $\left\{P_{i}^{r}\right\}$ is the restoring forces vector for the $i^{\text {th }}$ iteration.

Therefore, the Eq. (13) in the incremental form for any intermediary step (i.e., at the substep $n$ and the iteration $i$ ) has the following form:

$$
\left[\bar{K}_{i}\right]\left\{\Delta u_{i}\right\}-\Delta \zeta\left\{P^{a}\right\}=\left(\zeta_{n}+\zeta_{i}\right)\left\{P^{a}\right\}-\left\{P_{i}^{r}\right\}
$$

The incremental load factor (i.e., $\Delta \zeta$ ) is evaluated by the arc-length $\left(l_{i}\right)$ for the $i^{t h}$ iteration, as reported by Forde \& Stiemer [68], and given as:

$$
l_{i}^{2}=\Delta \zeta_{i}^{2}+\beta^{2}\left\{\Delta u_{n}\right\}^{T}\left\{\Delta u_{n}\right\}
$$

where, $\beta$ represents the scaling factor and $\Delta u_{n}$ is the sum of all the displacement increments $\Delta u_{i}$ up to $i^{\text {th }}$ iteration of the current load step.

The convergence for each iteration process is checked by following the error tolerance procedure:

$$
\|R\| \leq \alpha\|\Delta P\|
$$

where $R$ refers to residual force at each iteration (i.e., $\left.\left[\bar{K}_{i}\right]\left\{\Delta u_{i}\right\}-\left\{\Delta P_{i}\right\}\right)$ and $\alpha$ is a tolerance parameter which is chosen as $10^{-4}$.

FEM based software ANSYS is used to carry out the buckling and postbuckling study of FG-CNT-reinforced nanocomposite plate through a macro written in APDL (i.e., ANSYS Parametric Design Language).

\section{Verification Studies}

\subsection{For the Characterization of Nanocomposite}

To verify the procedure followed in the current paper to characterize nanocomposite material, a Mg- ESF nanocomposite system is considered and its effective elastic modulus obtained through FEM (refer Section 3.2) is compared with the value obtained through semi-empirical Tsai-Pagano method and also with the available experimental result in the literature. Zig-zag CNT of chirality $(50,50)$ is reinforced into the $\mathrm{Mg}$ matrix material. The material constants of CNT and Mg matrix are given below:

Matrix: Young modulus $E_{m}=45 \mathrm{GPa}$, Poisson's ratio $v=$ 0.3 ,

CNT: Young modulus $E_{f}=1 \mathrm{TPa}$, Poisson's ratio $v=0.3$, and, the geometric dimensions taken for CNT are as follows:

Length $L_{C N T}=100 \mathrm{~nm}$, Thickness of CNT, $t=0.34 \mathrm{~nm}$. Initially, an interphase zone between CNT and Mg matrix is characterized in terms of its elastic modulus and thickness (i.e., equilibrium distance, $h_{0}$ ) computed using Eqs. (1) \& (2), respectively. The required values of LJ potential parameters, i.e., vdW radius $(\sigma) \&$ bond energy $(\epsilon)$ [69], and the density \& atomic mass unit of $\mathrm{Mg}$ matrix are given in Table 1 . The value of volume density $\rho_{m}$, defined as the number of atoms per unit matrix volume, of $\mathrm{Mg}$ matrix material is evaluated as the ratio of matrix mass density to the mass of one atom of the matrix material, as given in Table 1. For carbon atoms in CNT, the values of bond energy and vdW radius between a pair of carbon atoms are taken as: $\epsilon_{C}=0.002390 \mathrm{eV}$ and $\sigma_{C}=0.3415 \mathrm{~nm}$, respectively, and the value of the area density of carbon atoms in

\begin{tabular}{|c|c|c|c|}
\hline$\sigma\left(A^{0}\right)$ & $\varepsilon[\mathrm{eV}]^{*}$ & $\begin{array}{l}\text { density } \\
\left(\mathrm{g} / \mathrm{cm}^{3}\right)\end{array}$ & 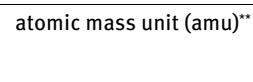 \\
\hline 3.0030 & 0.0012 & 1.7380 & 24.3050 \\
\hline
\end{tabular}
CNT is taken as $3.8177 \times 10^{19} \frac{1}{\mathrm{~m}^{2}}$ [70]. These vdW radii and bond energies of $\mathrm{Mg}$ and $\mathrm{C}$ atoms are utilized to evaluate the vdW radius and bond energy for the interphase region (i.e., $\sigma_{I}$ and $\epsilon_{I}$ ) using LB mixing rule.

Table 1: Potential parameters, density and atomic mass unit of Magnesium $(\mathrm{Mg})$ 
The Young's modulus of the hypothetical material of interphase zone and the corresponding thickness are evaluated as $3.1885 \mathrm{GPa}$ and $0.2755 \mathrm{~nm}$, respectively. These properties of interphase zone are further employed to model and characterize an ESF for its elastic modulus (i.e., $\left.E_{E S F}\right)$ and radius by following the procedure mentioned in Section 2. The obtained values of $E_{E S F}$ and radius of ESF are $532.7409 \mathrm{GPa}$, and $2.1045 \mathrm{~nm}$, respectively.

Table 2: Comparison of elastic modulus (in GPa) of Mg-ESF nanocomposite.

\begin{tabular}{cccccccc}
\hline \multicolumn{4}{c}{$\begin{array}{c}\text { Based on FEM procedure of the } \\
\text { present study }\end{array}$} & $\begin{array}{c}\text { Tsai- } \\
\text { Pagano } \\
\text { method }\end{array}$ & Ref.[71] & $\begin{array}{c}\text { \%age } \\
\text { deviation }\end{array}$ \\
\hline$E_{x}$ & $E_{y}$ & $E_{z}$ & $E_{a v}$ & $E$ & $E$ & $\begin{array}{l}\text { Tsai- } \\
\text { Pagano } \\
\text { method }\end{array}$ & $\begin{array}{l}\text { Reference } \\
\text { results }\end{array}$ \\
\hline 36.9807 & 37.2237 & 37.7045 & 37.3029 & 39.1721 & 38.6000 & 4.7717 & 3.3603 \\
\hline
\end{tabular}

Thereafter, ESFs are randomly-positioned \& -oriented into the matrix material to form an isotropic RVE using RSA technique to characterize the Mg- ESF nanocomposite material system for its elastic modulus. The obtained value of elastic modulus of nanocomposite is compared in Table 2 with the value obtained from semi-empirical TsaiPagano method as well as with the experimental value reported in Ref. [71]. As observed in Table 2, a good agreement can be seen in the compared values of elastic modulus of nanocomposite. It is to mention here that the same procedure is utilized in Section 9.2 of the present study to characterize Mg-ESF nanocomposite material for its stiffness properties.

\subsection{Postbuckling Analysis}

Buckling and postbuckling response of FG-ESF-reinforced nanocomposite plate are studied using FEM-based ANSYS software, and to verify the process an isotropic and homogeneous, simply-supported square plate under uniaxial edge compression is considered. The obtained buckling load and postbuckling response are compared with those reported by Sundaresan et al. [72] and Le-manh and Lee [73]. The material properties and width-to-thickness ratio taken for comparison purpose are the same as used by Sundaresan et al.[72] and Le-manh and Lee [73], and are given below:

$$
E=3 \times 10^{6}
$$

psi, $v=0.25, \frac{b}{h}=50$.
While comparing, the results - the applied uni-axial edge compressive load $N_{x}$ and the corresponding maximum transverse deflection of plate $\left(w_{\max }\right)$ - are normalized as below:

$$
\lambda=\frac{N_{x} b^{2}}{\pi^{2} D}, W^{\star}=\frac{w_{\max }}{h},
$$

where $D$, the flexural rigidity of plate, is given by $\frac{E h^{3}}{12\left(1-v^{2}\right)}$, and $b$ represents the side of the square plate, and $h$ is the thickness of the plate.

A good agreement of buckling load and postbuckling response obtained in the present study with those obtained by Sundaresan et al. [72] and Le-manh and Lee [73] can be seen in Fig. 7 .

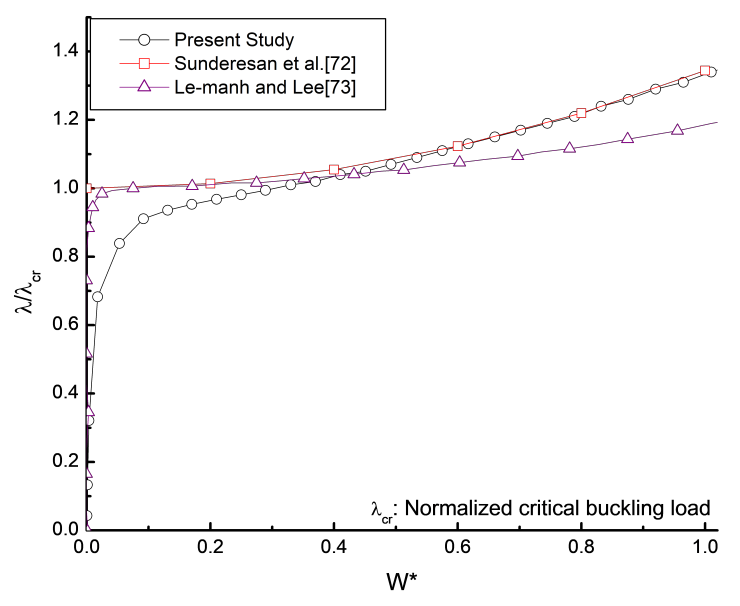

Fig. 7: Validation of buckling and postbuckling behavior of all edges simply-supported isotropic and homogeneous plate under uni-axial compression.

\section{Problem Definition}

In this paper, initially an ESF is formed to represent a CNT along with interphase zone. $\mathrm{Mg}$ is taken as matrix material. The isotropic effective material constants of heterogeneous nanocomposite material are estimated by the proper application of periodic boundary conditions on an RVE containing randomly-oriented and -positioned ESFs and generated through RSA technique demonstrated in Figs. 3 \& 4. For different volume fractions of ESF reinforcement, the obtained material constants of ESFs-reinforced $\mathrm{Mg}$ nanocomposite are presented and discussed in Section 9.1. 
Thereafter, the effective material constants of nanocomposite material are further utilized to study the buckling and postbuckling behaviour of FG-ESFreinforced nanocomposite plate. The square nanocomposite plate having side (i.e., b) $279 \mathrm{~mm}$ and thickness $5.58 \mathrm{~mm}$ (to keep width-to-thickness ratio equal to 50 for a thin plate) is utilized to study the postbuckling behaviour of FG-ESF-reinforced nanocomposite plate under different boundary and loading conditions. The effects of various parameters, viz. perfect \& imperfect bonding, type of ESF distribution (i.e., FG-A, FG-B and FG-C), ESF-alignment, geometric parameters (i.e., aspect ratio and width-to-thickness ratio of plate) and loading \& boundary conditions on buckling and postbuckling response of FG-ESF-reinforced nanocomposite plates, are studied and discussed in Section 9.2.

Five different flexural boundary conditions designated as: SSSS, SSSC, SCSC, SCCC and CCCC are considered for studying the effect of boundary conditions on buckling and postbuckling behavior of FG-ESF nanocomposite plate. Where SSSS denotes a plate with all edges simply-supported, SSSC means a plate with three edges (i.e., $x=b, y=0, y=b$ ) simply-supported and one edge (i.e., $x=0$ ) clamped, SCSC specifies a plate with two longitudinal edges $(y=0$ and $y=b)$ simply-supported and other two edges (i.e., $x=O$ and $x=b$ ) clamped, SCCC represents one edge (i.e., $y=0$ ) simply-supported and all other edges clamped, and CCCC designate a plate with all edges clamped. It is further to mention here that in all the above stated boundary conditions the in-plane boundary conditions on all edges related the displacements $u$ and $v$ in $x$ and $y$ - directions, respectively, are identical and specified as:- at edge $x=0: u=0 \& v \neq 0$, at edge $x=b: \psi=0 \& v \neq 0$, at edge $y=0: u \neq 0 \& v=0$, and at edge $y=b: u \neq 0 \& v \neq 0$.

The uni-axial compression load per unit width is applied on the edge $x=b$ while constraining the movement of the edge $x=O$ in $x$ - direction (i.e., taking $u=0$ ). The bi-axial compression load per unit width is applied on the edges $x$ $=b \& y=b$ while constraining the movement of the edges $x=0 \& y=0$ in $x$ - \& $y$ - directions, respectively. It is to be noted that except the study on effect of boundary condition on postbuckling behavior of FG-ESF nanocomposite plate, all other studies are conducted for SSSS boundary condition.

\section{Results and Discussions}

\subsection{Effective Material Constants of ESF/CNT Nanocomposite}

In this section, initially the effective material constants of CNT-reinforced nanocomposite are estimated using FEM for various volume fractions of reinforcement (taken in the range 1-5\%) without considering the interfacial effect between CNT and matrix material. The perfectlybonded CNT-reinforced nanocomposite RVE is modeled by the Boolean-based RSA technique, as discussed in Section 3.1. Thereafter, the effective material constants of perfectly-bonded CNT-reinforced nanocomposite material are obtained through the homogenization technique as discussed in Section 3.2 and the evaluated effective material constants are listed in Table 3.

Thereafter, the modelling of ESF-reinforced nanocomposite is performed by the Boolean-based RSA technique, for the volume fractions taken in the same range (i.e., 1-5\%). Table 4 represents the effective material constants of randomly-oriented \& -positioned ESF-reinforced nanocomposite. As observed from Tables 3 \& 4 that the effect of interphase zone results in substantial reduction in stiffness properties of randomly-oriented \& -positioned ESF-reinforced Mg-nanocomposite. In order to study the effect of alignment of nanofiller on the stiffness properties of nanocomposite, the aligned (in $x$-direction) ESFreinforced RVE is also modelled and the obtained effective material constants are given in Table 5. It can be observed from the Table 5 that ESF-alignment leads to enhanced elastic modulus of nanocomposite material in the direction of alignment as compared to the randomly-oriented \& -positioned ESF-reinforced nanocomposites.

\subsection{Postbuckling Behavior of FG-CNT/ESF Nanocomposite Plate}

The effective elastic constants of FG-CNT/ESF nanocomposite obtained in the previous section are utilized further in this section to study the effects of perfect \& imperfect bonding, type of ESF distribution (i.e., FG-A, FG-B and FG-C), ESF-alignment, geometric parameters (i.e., aspect ratio and width-to-thickness ratio) and loading \& boundary conditions on buckling and postbuckling responses of FG-ESF-reinforced nanocomposite plates. Except the study on the effect of type of distribution of ESF on postbuckling behavior of nanocomposite plate, all other studies are conducted for FG-A type distribution of FG-ESF reinforced 
Table 3: Effective material constants of randomly-oriented \& -positioned CNT-reinforced Mg-nanocomposites (i.e., without interphase effect).

\begin{tabular}{cccccccccc}
\hline \multirow{2}{*}{$\begin{array}{c}\text { Volume } \\
\text { fraction of } \\
\text { CNT }\end{array}$} & \multicolumn{8}{c}{ Effective Material Constants } \\
\cline { 2 - 11 } & $E_{x}$ & $E_{y}$ & $E_{z}$ & $G_{x y}$ & $G_{x z}$ & $G_{y z}$ & $v_{x y}$ & $v_{x z}$ & $v_{y z}$ \\
\hline $1 \%$ & 46.5822 & 46.6169 & 47.2021 & 17.9146 & 18.0311 & 17.9931 & 0.3009 & 0.2967 & 0.2943 \\
$2 \%$ & 48.1092 & 48.3407 & 49.5769 & 18.6468 & 18.7467 & 18.6140 & 0.3010 & 0.2936 & 0.2892 \\
$3 \%$ & 49.5994 & 50.0078 & 51.8595 & 19.9089 & 19.3128 & 19.3475 & 0.3019 & 0.2897 & 0.2844 \\
$4 \%$ & 51.9137 & 51.8671 & 52.7604 & 21.1649 & 20.2963 & 20.1375 & 0.3021 & 0.2843 & 0.2878 \\
$5 \%$ & 53.3892 & 54.3823 & 54.1574 & 22.1526 & 21.3895 & 21.5666 & 0.3028 & 0.2808 & 0.2891 \\
\hline
\end{tabular}

Table 4: Effective material constants of randomly-oriented \& -positioned ESF-reinforced Mg-nanocomposite.

\begin{tabular}{|c|c|c|c|c|c|c|c|c|c|}
\hline \multirow{3}{*}{$\begin{array}{l}\text { Volume } \\
\text { fraction } \\
\text { of CNT }\end{array}$} & \multicolumn{9}{|c|}{ Effective material constants } \\
\hline & \multicolumn{6}{|c|}{ Elastic moduli (GPa) } & \multicolumn{3}{|c|}{ Poisson's ratio } \\
\hline & $E_{x}$ & $E_{y}$ & $E_{z}$ & $G_{x y}$ & $G_{x z}$ & $G_{y z}$ & $v_{x y}$ & $v_{x z}$ & $v_{y z}$ \\
\hline $1 \%$ & 46.1309 & 46.1735 & 46.4450 & 17.7219 & 17.8163 & 17.8083 & 0.3003 & 0.2980 & 0.2969 \\
\hline $2 \%$ & 47.1353 & 47.3142 & 47.8886 & 18.1182 & 18.1919 & 18.2669 & 0.3002 & 0.2961 & 0.2942 \\
\hline $3 \%$ & 48.3588 & 48.4802 & 49.4529 & 18.6611 & 18.8746 & 18.7251 & 0.3009 & 0.2938 & 0.2908 \\
\hline $4 \%$ & 49.5565 & 49.7141 & 50.8203 & 19.1754 & 19.4340 & 19.2626 & 0.3007 & 0.2934 & 0.2891 \\
\hline $5 \%$ & 50.7499 & 51.1639 & 51.8227 & 20.1464 & 20.1582 & 20.0082 & 0.2991 & 0.2939 & 0.2908 \\
\hline
\end{tabular}

Table 5: Effective material constants of aligned and randomly-positioned ESF-reinforced Mg-nanocomposite.

\begin{tabular}{cccccccccc}
\hline \multirow{2}{*}{$\begin{array}{c}\text { Volume } \\
\text { fraction of }\end{array}$} & \multicolumn{10}{c}{ Effective material constants } \\
\cline { 2 - 12 } CNT & $E_{x}$ & $E_{y}$ & $E_{z}$ & $G_{x y}$ & $G_{x z}$ & $G_{y z}$ & $v_{x y}$ & $v_{x z}$ & $v_{y z}$ \\
\cline { 2 - 12 } & 49.1445 & 45.9046 & 45.9126 & 17.6006 & 17.7247 & 17.5439 & 0.2993 & 0.2995 & 0.3072 \\
$2 \%$ & 53.3868 & 46.7818 & 46.7914 & 17.9066 & 18.0179 & 17.7615 & 0.2992 & 0.2994 & 0.3132 \\
$3 \%$ & 57.9718 & 47.6872 & 47.6649 & 18.2293 & 18.3298 & 18.0865 & 0.2995 & 0.2999 & 0.3189 \\
$4 \%$ & 62.6135 & 48.5461 & 48.5226 & 18.5354 & 18.6987 & 18.3493 & 0.2997 & 0.3001 & 0.3231 \\
$5 \%$ & 66.8689 & 49.4350 & 49.4243 & 18.8669 & 18.9569 & 18.5513 & 0.2998 & 0.2998 & 0.3260 \\
\hline
\end{tabular}

nanocomposite plate. The uni-axial/bi-axial compressive loads $(N)$ and the maximum transverse deflection $\left(w_{\max }\right)$ are normalized as follows:

$$
\lambda=\frac{N b^{2}}{E_{m} h^{3}}
$$

(with $N=N_{x}$ for uni-axial loading, and $N=N_{x}=N_{y}$ for bi-axial loading); $W^{\star}=\frac{w_{\max }}{h}$, where, $E_{m}$ represents the Young's modulus of matrix material, $b$ is the side of the square plate, and $h$ represents the thickness of the plate.

\subsubsection{Convergence study}

To fix the number of layers of FG-CNT-reinforced nanocomposite plate [to model the actual non-homogeneous FGCNT-reinforced nanocomposite plate with continuously varying properties (only in thickness direction) plate into a laminated plate with multiple perfectly-bonded layers of isotropic material having layer-wise constant composition, but varying along thickness], a convergence study 
is conducted for an SSSS FG-A (refer Fig. 6) type CNTreinforced nanocomposite plate for 10,12 and 14 layers. The convergence of buckling load and postbuckling strength (corresponding to $W^{*}=0.5$ ) are checked for SSSS FG-A type CNT-reinforced nanocomposite plate with $b / h=50$, under uni-axial compression. Results of convergence study are shown in Table 6. It can be observed from Table 6 that results for buckling load and postbuckling strength (corresponding to $W^{\star}=0.5$ ) for the CNTreinforced nanocomposite plate are converged reasonably for 12 layers.

Table 6: Convergence study for buckling load and postbuckling strength (corresponding to $W^{\star}=0.5$ ) for SSSS FG-A CNT-reinforced nanocomposite square plate under uni-axial compression, for $b / h=50$.

\begin{tabular}{ccc}
\hline No. of layers & Non-dimensional buckling load & $\begin{array}{c}\text { Non-dimensional postbuckling strength } \\
\text { at } \mathbf{W}^{*}=0.5\end{array}$ \\
\hline 10 & 3.34 & 4.22 \\
12 & 3.32 & 4.19 \\
14 & 3.31 & 4.18 \\
\hline
\end{tabular}

\subsubsection{Postbuckling studies}

The effect of type of bonding (i.e., perfect and imperfect) between CNT and matrix material on the postbuckling response of simply-supported FG nanocomposite plate is studied and shown in Fig. 8. It can be seen from Fig. 8 that the nanocomposite plate having perfect bonding between CNT and matrix material has the highest buckling load and postbuckling strength corresponding to a particular value of transverse deflection for all three types of nanofiller distribution in Mg matrix (i.e., A-, B- and Ctype). For instance, perfectly bonded FG-A type nanocomposite plate have approximately $3.01 \%$ and $5.49 \%$ more buckling load and postbuckling strength (corresponding to $\mathrm{W}^{\star}=0.5$ ), respectively, than the imperfectly bonded FGA type nanocomposite plate. This reduced enhancement in the buckling load and postbuckling strength can be attributed to the reduced enhancement in stiffness properties of nanocomposite caused by weak interphase between CNT and Mg matrix material that would result in poor load transfer to the CNT in the case of imperfect bonding. This finding is in good concurrence with the similar observations reported in the literature [74, 75]. It can also be observed from Fig. 8 that for different types of FG nanocomposite (i.e., A-, B- and C-type) plates, the FG-B type nanocomposite plate has the lowest buckling load and postbuckling strength, while the FG-A type nanocomposite plate has the highest buckling load and postbuckling strength. This is due to the fact that the higher volume fraction of nanofillers near to top and bottom surfaces (as in FG-A type) of nanocomposite plate makes top and bottom surfaces more stiff to deform than mid-surface.

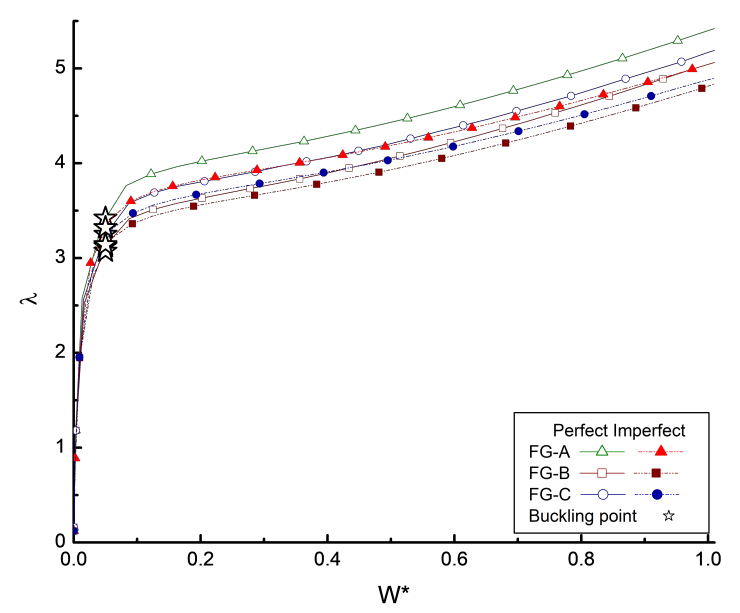

Fig. 8: A comparative load-deflection behavior of FG-CNT/ESFreinforced $\mathrm{Mg}$ nanocomposite plate.

Under uni-axial compression, the effect of ESFalignment on the buckling load and postbuckling response of FG-ESF nanocomposite plate are given in Table 7. It can be observed from the Table 7 that the ESFalignment (but randomly positioned) have only marginal positive effect on the buckling load and postbuckling response of FG-ESF-reinforced Mg nanocomposite plate as compared to the randomly-oriented \& -positioned FG-ESF nanocomposite plate. This finding can be explained by the fact that the aligned ESF-reinforced nanocomposite possess higher axial modulus (i.e., $E_{x}$ ) than uniformlyoriented \& -positioned ESF reinforced nanocomposite plates and, therefore, offers better resistance to in-plane compressive loading. It can also be seen from the Table 7 that A-type distribution of ESFs in matrix material offer better resistance to in-plane compressive loading (i.e., $x$-direction) than B- and C-type distributions in FG-ESF nanocomposite having randomly -positioned \& -oriented as well as aligned ESFs.

The effects of geometric parameters (i.e., aspect and width-to-thickness ratios) on the buckling and postbuckling behavior of FG-ESF-reinforced nanocomposite plate are shown in Fig. 9 and Table 8, respectively. The results 
Table 7: Effect of ESF-alignment on the buckling load and postbuckling strength of SSSS FG-ESF-reinforced Mg nanocomposite plate.

\begin{tabular}{|c|c|c|c|c|c|c|c|c|}
\hline \multirow[t]{3}{*}{$\begin{array}{l}\text { Type of CNT } \\
\text { distribution }\end{array}$} & \multicolumn{4}{|c|}{ Buckling load } & \multicolumn{4}{|c|}{$\begin{array}{l}\text { Postbuckling strength } \\
\qquad \text { at } W^{*}=0.5\end{array}$} \\
\hline & \multicolumn{2}{|c|}{$\begin{array}{l}\text { Randomly-oriented \& - } \\
\text { positioned ESFs }\end{array}$} & \multicolumn{2}{|c|}{$\begin{array}{l}\text { Aligned \& randomly - } \\
\text { positioned ESFs }\end{array}$} & \multicolumn{2}{|c|}{$\begin{array}{l}\text { Randomly-oriented \& - } \\
\text { positioned ESFs }\end{array}$} & \multicolumn{2}{|c|}{$\begin{array}{l}\text { Aligned \& randomly - } \\
\text { positioned ESFs }\end{array}$} \\
\hline & $\begin{array}{c}\text { Dimensional } \\
\qquad\left(N_{x}\right)\end{array}$ & $\begin{array}{c}\text { Non- } \\
\text { dimensional } \\
(\lambda)\end{array}$ & $\begin{array}{c}\text { Dimensional } \\
\left(N_{x}\right)\end{array}$ & $\begin{array}{c}\text { Non- } \\
\text { dimensional } \\
(\lambda)\end{array}$ & $\begin{array}{c}\text { Dimensional } \\
\qquad\left(N_{x}\right)\end{array}$ & $\begin{array}{c}\text { Non- } \\
\text { dimensional } \\
(\lambda)\end{array}$ & $\begin{array}{c}\text { Dimensional } \\
\qquad\left(N_{x}\right)\end{array}$ & $\begin{array}{c}\text { Non- } \\
\text { dimensional } \\
(\lambda)\end{array}$ \\
\hline A & 333.4608 & 3.32 & 339.4870 & 3.38 & 420.8436 & 4.19 & 427.8744 & 4.26 \\
\hline B & 305.3376 & 3.04 & 308.3508 & 3.07 & 392.7204 & 3.91 & 394.7292 & 3.93 \\
\hline C & 309.3552 & 3.08 & 311.3640 & 3.10 & 396.7380 & 3.95 & 399.7512 & 3.98 \\
\hline
\end{tabular}

Table 8: Effect of $b / h$ ratio on the buckling load and postbuckling strength of SSSS A-type FG-ESF-reinforced Mg nanocomposite plate.

\begin{tabular}{ccccc}
\hline$b / h$ & \multicolumn{2}{c}{ Buckling load } & \multicolumn{2}{c}{$\begin{array}{c}\text { Postbuckling strength } \\
\text { at } W^{*}=0.5\end{array}$} \\
\cline { 2 - 5 } & $\begin{array}{c}\text { Dimensional } \\
\left(N_{x}\right)\end{array}$ & $\begin{array}{c}\text { Non- } \\
\text { dimensional } \\
(\lambda)\end{array}$ & $\begin{array}{c}\text { Dimensional } \\
\left(N_{x}\right)\end{array}$ & $\begin{array}{c}\text { Non- } \\
\text { dimensional } \\
(\lambda)\end{array}$ \\
\hline 25 & 2563.2288 & 3.19 & 3206.0448 & 3.99 \\
50 & 333.4608 & 3.32 & 420.8436 & 4.19 \\
100 & 44.0681 & 3.51 & 55.7442 & 4.44 \\
200 & 5.5556 & 3.54 & 7.0308 & 4.48 \\
\hline
\end{tabular}

are obtained for A-type FG-CNT-reinforced nanocomposite plate.

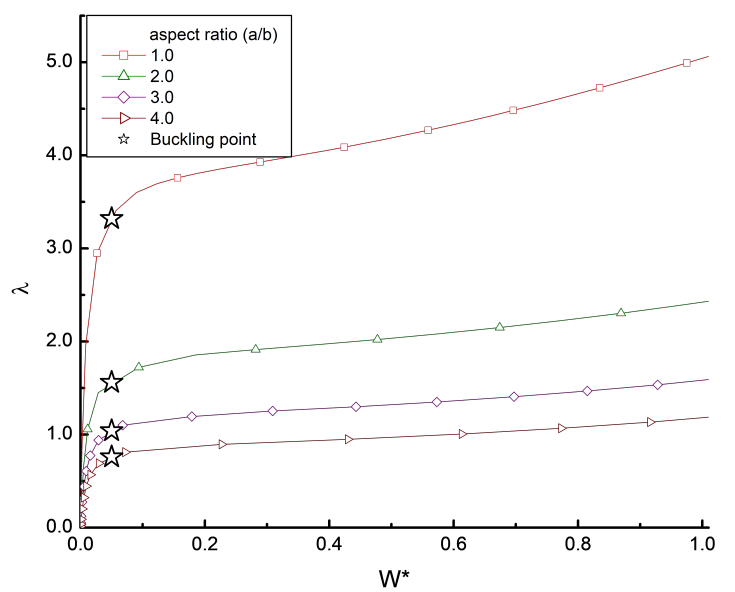

Fig. 9: Effect of aspect ratio $(a / b)$ on the postbuckling response of SSSS A-type FG-CNT-reinforced Mg nanocomposite plate.
It can be observed from Fig. 9 that with the increase in aspect ratio of nanocomposite plate, the buckling load and postbuckling strength of the nanocomposite plate decreases and for higher aspect ratios, nanocomposite plate posses only marginal postbuckling strength. The differences between the buckling loads and the postbuckling strengths of FG-ESF nanocomposite plates of lower aspect ratios are substantial, and these differences decrease for the higher aspect ratios, as shown in Fig. 9; therefore, it is expected that the nanocomposite plates of very high aspect ratios (beyond 4.0) would possess almost the same buckling load and postbuckling strength, and in such cases the nanocomposite plate behaves more or less as a column.

The effect of the width-to-thickness ratio (i.e., $b / h$ ) on the buckling load and postbuckling strength (at $W^{\star}=0.5$ ) of A-type FG-ESF-reinforced nanocomposite plate is plotted in Table 8. It is evident from Table 8 that with the increase in thickness of the nanocomposite plate, its buckling load and postbuckling strength are increased substantially.

The effects of different boundary conditions on buckling and postbuckling behavior of A-type FG-ESF Mg nanocomposite plate under uni-axial compression are studied and plotted in Fig. 10. It can also be observed from Fig. 10 that boundary conditions have a significant effect on buckling load and postbuckling response of nanocomposite plate. The buckling load and postbuckling strength at a particular value of maximum transverse deflection of FG-ESF-reinforced $\mathrm{Mg}$ nanocomposite plate show an increasing trend as the edge conditions are successively changed from simply-supported to clamped, i.e., the buckling load and postbuckling strength of SSSC nanocomposite plate are more than that of SSSS plate.

The effects of loading conditions (i.e., uni-axial and bi-axial compression) on the load-deflection response of SSSS A-type FG-ESF-reinforced nanocomposite are shown 


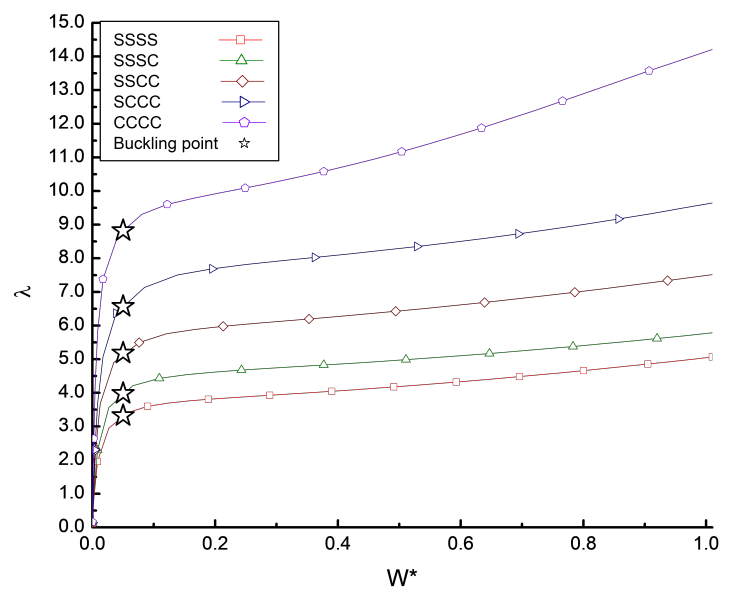

Fig. 10: Effects of boundary conditions on buckling and postbuckling behavior of A-type FG-ESF nanocomposite plate subjected to the uni-axial compression load.

in Fig. 11. As seen from Fig. 11, the buckling load and postbuckling strength for the FG-ESF-reinforced nanocomposite plate under bi-axial compressive load are much lower than those under uni-axial compressive load.

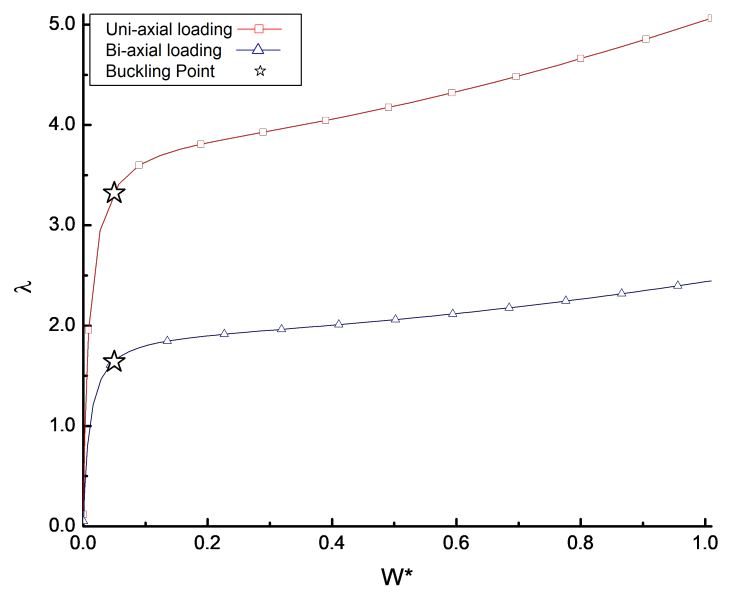

Fig. 11: Comparison of buckling and postbuckling behavior of SSSS A-type FG-ESF-reinforced nanocomposite plate subjected to uniaxial and bi-axial compression.

\section{Concluding remarks}

In the current study, a cohesive zone model is employed to characterize the interphase region between CNT and $\mathrm{Mg}$ matrix material in terms of its elastic modulus and thickness. Thereafter an equivalent solid fiber (ESF) containing CNT and corresponding interphase zone is modeled, and that are dispersed randomly into the matrix material by Boolean based RSA technique to make a nanocomposite. The effective stiffness properties of the nanocomposite material are evaluated with the application of finite element method (FEM) based numerical homogenization technique for different volume fractions of CNT reinforcement. The obtained stiffness properties of nanocomposite material are further utilized to model and study the buckling and postbuckling behaviour of functionally graded (i.e., FG) CNT-reinforced nanocomposite plate, with and without considering interphase effect, under in-plane compressive loading. The non-linear FEM formulation for plate analysis was based on the first-order shear deformation theory and von Karman's assumptions. Arc-length method is utilized to solve the resulting nonlinear finite element algebraic equations. Different studies are performed to study the effects of perfect and imperfect bonding between CNT and matrix material, CNTalignment, geometric parameters (i.e., aspect ratio and width-to-thickness ratio), boundary conditions and type of loading (i.e., uni-axial and bi-axial compression) on the postbuckling behaviour of FG-CNT-reinforced nanocomposite plate. Based on the studies conducted following conclusions are drawn:

- $\quad$ Effect of interphase between CNT and Mg matrix results in reduced buckling load and postbuckling strength of FG-CNT-reinforced nanocomposite plate as compared to perfectly bonded FG-CNT-reinforced nanocomposite plate.

- Higher volume fraction of CNTs near top and bottom surfaces than the middle portion of nanocomposite plate provide better resistance to buckling and postbuckling.

- Buckling load and postbuckling strength of FG-CNTreinforced $\mathrm{Mg}$ nanocomposite plate under uni-axial compression load is marginally improved when the CNTs are aligned in the direction of loading than that of the nanocomposite plate having randomlyoriented \& -positioned CNTs.

- $\quad$ FG-CNT-reinforced nanocomposite plates having high aspect ratios possess almost same buckling load and postbuckling strength, thus indicating that such plates would behave more or less like a column 
possessing only marginal postbuckling strength beyond buckling.

- Increase in the thickness of the FG-CNT-reinforced nanocomposite plate results in substantial improvement in its buckling load and postbuckling strength.

- Increasing the rigidity of boundary edges of the plate by changing the edge conditions successively from all edges simply-supported to all edges clamped will show increasing trend in its buckling load and postbuckling strength at a particular value of maximum transverse deflection.

Acknowledgement: The authors would like to kindly acknowledge the support provided by the Indian Space Research Organization, Department of Space, Govt. of India under contract number ISRO/RES/3/724/16-17, and the Material Research Center (MRC) at Malaviya National Institute of Technology (MNIT) Jaipur.

\section{References}

[1] lijima S. Helical microtubules of graphitic carbon. Nature 1991, 354:56-8.

[2] Salvetat JP, Bonard JM, Thomson NH, Kulik AJ, Forr' L, Benoit W, et al. Mechanical properties of carbon nanotubes. Appl Phys A Mater Sci Process 1999, 69:255-60.

[3] Esawi AMK, Farag MM. Carbon nanotube reinforced composites: Potential and current challenges. Mater Des 2007, 28:2394-401.

[4] Kumar D, Srivastava A. Elastic properties of CNT- and graphene-reinforced nanocomposites using RVE. Steel Compos Struct 2016, 21:1085-103.

[5] Esawi AMK, Morsi K, Sayed A, Taher M, Lanka S. Effect of carbon nanotube ( CNT) content on the mechanical properties of CNT-reinforced aluminium composites. Compos Sci Technol 2010, 70:2237-41.

[6] Choi J, Shin H, Cho M. A Multiscale mechanical model for the effective interphase of SWNT/Epoxy nanocomposite. Polymer 2016, 89:159-71.

[7] Ma PC, Siddiqui NA, Marom G, Kim JK. Dispersion and functionalization of carbon nanotubes for polymer-based nanocomposites: A review. Compos Part A Appl Sci Manuf 2010, 41:1345-67.

[8] Tsai JL, Tzeng SH, Chiu YT. Characterizing elastic properties of carbon nanotubes/polyimide nanocomposites using multiscale simulation. Compos Part B 2010, 41:106-15.

[9] Shokrieh MM, Rafiee R. On the tensile behavior of an embedded carbon nanotube in polymer matrix with non-bonded interphase region. Compos Struct 2010, 92:647-52.

[10] Hernández-Pérez A, Avilés F. Modeling the influence of interphase on the elastic properties of carbon nanotube composites. Comput Mater Sci 2010, 47:926-33.
[11] Herasati S, Zhang LC, Ruan HH. A new method for characterizing the interphase regions of carbon nanotube composites. Int J Solids Struct 2014, 51:1781-91.

[12] Shokrieh MM, Rafiee R. Prediction of mechanical properties of an embedded carbon nanotube in polymer matrix based on developing an equivalent long fiber. Mech Res Commun 2010, 37:235-40.

[13] Rafiee R, Mahdavi M. Characterizing nanotube - polymer interaction using molecular dynamics simulation. Comput Mater Sci 2016, 112:356-63.

[14] Odegard GM, Clancy TC, Gates TS. Modeling of the mechanical properties of nanoparticle/polymer composites. Polymer 2005, 46:553-62.

[15] Jiang LY, Huang Y, Jiang H, Ravichandran G, Gao H, Hwang KC, et al. A cohesive law for carbon nanotube/polymer interfaces based on the van der Waals force. J Mech Phys Solids 2006, 54:2436-52.

[16] Tan H, Jiang LY, Huang Y, Liu B, Hwang KC. The effect of van der Waals-based interface cohesive law on carbon nanotubereinforced composite materials. Compos Sci Technol 2007, 67:2941-6.

[17] Zhao J, Jiang J-W, Jia Y, Guo W, Rabczuk T. A theoretical analysis of cohesive energy between carbon nanotubes, graphene and substrates. Carbon 2013, 57:108-19.

[18] Zhang Y, Zhao J, Jia Y, Mabrouki T, Gong Y, Wei N, et al. An analytical solution on interface debonding for large diameter carbon nanotube-reinforced composite with functionally graded variation interphase. Compos Struct 2013, 104:261-9.

[19] Xie X, Mai Y, Zhou X. Dispersion and alignment of carbon nanotubes in polymer matrix: A review. Mater Sci Eng R Reports 2005, 49:89-112.

[20] Zhang Q, Lippits DR, Rastogi S. Dispersion and rheological aspects of SWNTs in ultrahigh molecular weight polyethylene. Macromolecules 2006, 39:658-66.

[21] Mecklenburg M, Mizushima D, Ohtake N, Bauhofer W, Fiedler $B$, Schulte K. On the manufacturing and electrical and mechanical properties of ultra-high wt.\% fraction aligned MWCNT and randomly oriented CNT epoxy composites. Carbon 2015, 91:275-90.

[22] Rahman MM, Hosur M, Zainuddin S, Jahan N, Miller-Smith $E B$, Jeelani S. Enhanced tensile performance of epoxy and E-glass/epoxy composites by randomly-oriented aminofunctionalized MWCNTs at low contents. J Compos Mater 2014, 49:759-70.

[23] Wang S, Liang R, Wang B, Zhang C. Dispersion and thermal conductivity of carbon nanotube composites. Carbon 2009, 47:53-7.

[24] Esawi AMK, Morsi K, Sayed A, Taher M, Lanka S. The influence of carbon nanotube ( CNT) morphology and diameter on the processing and properties of CNT-reinforced aluminium composites. Compos Part A 2011, 42:234-43.

[25] Srivastava A, Kumar D. Postbuckling of nanocomposite plate reinforced with randomly oriented and dispersed CNTS modeled through RSA technique. Int I Multiscale Comput Eng 2016, 14:585-606.

[26] Abd El-Rahman Al, Tucker CL. Mechanics of random discontinuous long-fiber thermoplastics. Part II: Direct simulation of uniaxial compression. J Rheol 2013, 57:1463.

[27] Pan Y, lorga L, Pelegri AA. Numerical generation of a random chopped fiber composite RVE and its elastic properties. Com- 
pos Sci Technol 2008, 68:2792-8.

[28] Pan Y, lorga L, Pelegri AA. Analysis of 3D random chopped fiber reinforced composites using FEM and random sequential adsorption. Comput Mater Sci 2008, 43:450-61.

[29] Bailakanavar M, Liu Y, Fish J, Zheng Y. Automated modeling of random inclusion composites. Eng Comput 2012, 30:609-25.

[30] Abd El-Rahman Al, Tucker III CL. Mechanics of random discontinuous long-fiber thermoplastics-Part I: Generation and characterization of initial geometry. J Appl Mech 2013, 80:51007.

[31] Song W, Krishnaswamy V, Pucha R V. Computational homogenization in RVE models with material periodic conditions for CNT polymer composites. Compos Struct 2016, 137:9-17.

[32] Liu H, Zeng D, Li Y, Jiang L. Development of RVE-embedded solid elements model for predicting effective elastic constants of discontinuous fiber reinforced composites. Mech Mater 2016, 93:109-23.

[33] Khan SU, Pothnis JR, Kim J. Effects of carbon nanotube alignment on electrical and mechanical properties of epoxy nanocomposites. Compos Part A Appl Sci Manuf 2013, 49:2634.

[34] Ogasawara T, Moon S, Inoue Y, Shimamura Y. Mechanical properties of aligned multi-walled carbon nanotube / epoxy composites processed using a hot-melt prepreg method. Compos Sci Technol 2011, 71:1826-33.

[35] Bradford PD, Wang X, Zhao H, Maria J, Jia Q, Zhu YT. A novel approach to fabricate high volume fraction nanocomposites with long aligned carbon nanotubes. Compos Sci Technol 2010, 70:1980-5.

[36] Pal G, Kumar S. Multiscale modeling of effective electrical conductivity of short carbon fiber-carbon nanotube-polymer matrix hybrid composites. Mater Des 2016, 89:129-36.

[37] Joshi P, Upadhyay SH. Analysis of alignment effect on carbon nanotube layer in nanocomposites. Phys E Low-Dimensional Syst Nanostructures 2015, 66:221-7.

[38] Alva A, Bhagat A, Raja S. Effective moduli evaluation of carbon nanotube reinforced polymers using micromechanics. Mech Adv Mater Struct 2015, 22:819-28.

[39] Alibeigloo A, Liew KM. Elasticity solution of free vibration and bending behavior of functionally graded carbon nanotubereinforced composite beam with thin piezoelectric layers using differential quadrature method. Int J Appl Mech 2015, 7:1550002.

[40] Rafiee M, He XQ, Mareishi S, Liew KM. Modelling and stress analysis of smart CNTs/Fiber/Polymer multiscale composite plates. Int J Appl Mech 2014, 6:1450025.

[41] Vosoughi AR, Malekzadeh P, Banan MR, Banan MR. Thermal buckling and postbuckling of laminated composite beams with temperature-dependent properties. Int J Non Linear Mech 2012, 47:96-102.

[42] Malekzadeh P. Three-dimensional thermal buckling analysis of functionally graded arbitrary straight-sided quadrilateral plates using differential quadrature method. Compos Struct 2011, 93:1246-54.

[43] Shen HS, Zhu ZH. Postbuckling of sandwich plates with nanotube-reinforced composite face sheets resting on elastic foundations. Eur J Mech A/Solids 2012, 35:10-21.

[44] Foroughi H, Askariyeh H, Azhari M. Mechanical buckling of thick composite plates reinforced with randomly oriented, straight, single-walled carbon nanotubes resting on an elas- tic foundation using the finite strip method. J Nanomech Micromech 2013, 3:49-58.

[45] Malekzadeh P, Shojaee M. Buckling analysis of quadrilateral laminated plates with carbon nanotubes reinforced composite layers. Thin-Walled Struct 2013, 71:108-18.

[46] Shen HS. Nonlinear bending of functionally graded carbon nanotube-reinforced composite plates in thermal environments. Compos Struct 2009, 91:9-19.

[47] Lei ZX, Zhang LW, Liew KM. Elastodynamic analysis of carbon nanotube-reinforced functionally graded plates. Int J Mech Sci 2015, 99:208-17.

[48] Zhang LW, Song ZG, Liew KM. State-space Levy method for vibration analysis of FG-CNT composite plates subjected to inplane loads based on higher-order shear deformation theory. Compos Struct 2015, 134:989-1003.

[49] Lei ZX, Zhang LW, Liew KM, Yu JL. Dynamic stability analysis of carbon nanotube-reinforced functionally graded cylindrical panels using the element-free kp-Ritz method. Compos Struct 2014, 113:328-38.

[50] Lei ZX, Zhang LW, Liew KM. Free vibration analysis of laminated FG-CNT reinforced composite rectangular plates using the kp-Ritz method. Compos Struct 2015, 127:245-59.

[51] Shen H-S, Zhang C-L. Thermal buckling and postbuckling behavior of functionally graded carbon nanotube-reinforced composite plates. Mater Des 2010, 31:3403-11.

[52] Zhang LW, Lei ZX, Liew KM. Buckling analysis of FG-CNT reinforced composite thick skew plates using an element-free approach. Compos Part B Eng 2015, 75:36-46.

[53] Zhang LW, Liew KM. Postbuckling analysis of axially compressed CNT reinforced functionally graded composite plates resting on Pasternak foundations using an element-free approach. Compos Struct 2016, 138:40-51.

[54] Zhang LW, Liew KM, Reddy JN. Postbuckling of carbon nanotube reinforced functionally graded plates with edges elastically restrained against translation and rotation under axial compression. Comput Methods Appl Mech Eng 2016, 298:128.

[55] Srivastava A, Kumar D. A continuum model to study interphase effects on elastic properties of CNT/GS-nanocomposite. Mater Res Express 2017, 4:25036.

[56] White A. Intermolecular potentials of mixed systems: Testing the Lorentz-Berthelot mixing rules with ab initio calculations. 2000.

[57] Boda D, Henderson D. The effects of deviations from LorentzBerthelot rules on the properties of a simple mixture. Mol Phys An Int J Interface Between Chem Phys 2008, 106:2367-70.

[58] Joshi UA, Joshi P, Harsha SP, Sharma SC. Evaluation of the mechanical properties of CNT based composites using hexagonal RVE. J Nanotechnol Eng Med 2010, 1:1-7.

[59] Chen XL, Liu YJ. Square representative volume elements for evaluating the effective material properties of carbon nanotube-based composites. Comput Mater Sci 2004, 29:111.

[60] Stern T, Teishev A., Marom G. Composites of polyethylene reinforced with chopped polyethylene fibers: Effect of transcrystalline interphase. Compos Sci Technol 1997, 57:1009-15.

[61] Kunanopparat T, Menut P, Morel MH, Guilbert S. Plasticized wheat gluten reinforcement with natural fibers: Effect of thermal treatment on the fiber/matrix adhesion. Compos Part A Appl Sci Manuf 2008, 39:1787-92. 
[62] Halpin JC, Kardos JL. The Halpin-Tsai Equations: A Review. Polym Eng Sci 1976, 16:344-52.

[63] Kaw AK. Mechanics of composite materials. CRC Press Taylor \& Francis Group; 2006.

[64] Kubiak T. Static and dynamic buckling of thin-walled plate structures. Springer International Publishing Switzerland; 2013.

[65] Allahyari H. Application of the finite element method to the postbuckling behaviour of thin plates containing imperfections. Cranfield Institute of Technology, 1978.

[66] Barbero EJ. Finite element analysis of composite materials. CRC Press Taylor \& Francis Group; 2008.

[67] Sharma K, Kumar D. Nonlinear stability analysis of perforated fgm plate under thermal load. Mech Adv Mater Struct 2018, 25:100-14.

[68] Forde BWR, Stiemer SF. Improved arc length orthogonality methods for nonlinear finite element analysis. Comput Struct 1987, 27:625-30.

[69] Fan J. Mutiscale Analysis of deformation and failure of materials. John Wiley \& Sons Ltd.; 2011.
[70] Lu WB, Wu J, Song J, Hwang KC, Jiang LY, Huang Y. A cohesive law for interfaces between multi-wall carbon nanotubes and polymers due to the van der Waals interactions. Comput Methods Appl Mech Eng 2008, 197:3261-7.

[71] Carreño-Morelli E, Yang J, Couteau E, Hernadi K, Seo JW, Bonjour C, et al. Carbon nanotube/magnesium composites. Phys Status Solidi 2004, 201:R53-54.

[72] Sundaresan P, Singh G, Venkateswara Rao G. Buckling and post-buckling analysis of moderately thick laminated rectangular plates. Comput Struct 1996, 61:79-86.

[73] Le-manh T, Lee J. Postbuckling of laminated composite plates using NURBS-based isogeometric analysis. Compos Struct 2014;109:286-93.

[74] Joshi P, Upadhyay SH. Effect of interphase on elastic behavior of multiwalled carbon nanotube reinforced composite. Comput Mater Sci 2014, 87:267-73.

[75] Kumar P, Srinivas J. Numerical evaluation of effective elastic properties of CNT-reinforced polymers for interphase effects. Comput Mater Sci 2014, 88:139-44. 